\title{
Complicações das vias aéreas relacionadas à intubação endotraqueal
}

\section{Airway complications associated with endotracheal intubation}

\author{
Regina H. G. Martins ${ }^{1}$ Norimar H. Dias ${ }^{2}$, \\ José R. C. Braz ${ }^{3}$, Emanuel C. Castilho ${ }^{4}$
}

Palavras-chave: intubação, vias aéreas, complicações, morbidade.

Key words: intubation, airway, complications, morbidity.

\section{Resumo / Summary}

escrevemos as principais complicações das vias aéreas relacionadas à intubação endotraqueal, por meio de revisão da literatura e apresentação dos resultados de pesquisas clínicas e experimentais realizadas pelo nosso grupo de estudo. Procuramos alertar os profissionais de saúde quanto à alta incidência de complicações secundárias à intubação, as quais podem ser reduzidas com a adoção de medidas profiláticas simples e de cunho prático, estabelecidas após a compreensão da fisiopatologia das lesões.
W. e reviewed the main airway complications associated with endotracheal intubation, presented some results of our researches and alert health professionals for the high incidence of airway injuries. The knowledge of the physiopathology of these injuries will help to proper prophylactic and practice conducts to prevent the airway complications associated with endotracheal intubation.

1 Professora Assistente Doutora da Disciplina de O torrinolaringologia da Faculdade de Medicina de Botucatu (UNESP).

2 Ex-residente da Disciplina de Otorrinolaringologia, Mestre em Cirurgia, Faculdade de Medicina de Botucatu (UNESP). ${ }^{3}$ Professor Titular do Departamento de Anestesiologia da Faculdade de Medicina de Botucatu (UNESP).

${ }^{4}$ Médico da Disciplina de O torrinolaringologia, Doutor em Cirurgia, Faculdade de Medicina de Botucatu (UNESP).

Trabalho realizado pela Disciplina de Otorrinolaringologia e Departamento de Anestesiologia da Faculdade de Medicina de Botucatu (UNESP)

Endereço para correspondência: Regina Helena Garcia Martins, Disciplina de Otorrinolaringologia, Departamento de

Oftalmologia, Otorrinolaringologia e Cirurgia de Cabeça e Pescoço da Faculdade de Medicina de Botucatu, Distrito de Rubião Junior, Botucatu (SP). 18618-970

Fonefax: (0xx14)3811-6256 - E-mail: rmartins@fmb.unesp.br.

Artigo recebido em 25 de fevereiro de 2004. Artigo aceito em 28 de maio de 2004. 


\section{INTRODUÇÃO}

A intubação endotraqueal permite a assistência ventilatória em pacientes anestesiados ou sob ventilação mecânica, podendo ser de curta ou longa duração. A presença de tubos oro ou nasotraqueais em contato direto com as estruturas das vias aéreas pode provocar lesões de mucosa, decorrentes, principalmente, de intubações traumáticas e prolongadas, da utilização de tubos de grande calibre e da elevada pressão no balonete das sondas. O bserva-se também prejuízo ao condicionamento do ar, uma vez que as fossas nasais, não entrando em contato com 0 ar inalado, por causa da presença do tubo, ficam impedidas de realizar o importante papel de filtração, umidificação e aquecimento dos gases inalados.

Nas últimas décadas, as tentativas de redução da morbidade associada à intubação puderam ser evidenciadas pelo desenvolvimento de novos tipos de balonetes dos tubos endotraqueais (mais extensos e mais complacentes), pela disponibilidade dos novos protótipos de sondas e pelo acoplamento de umidificadores aquecidos aos sistemas de ventilação mecânica. No mesmo sentido, têm sido enfatizadas as orientações a residentes, médicos e enfermeiros quanto aos cuidados necessários durante a introdução da sonda traqueal, à escolha do calibre ideal do tubo e às técnicas adequadas de aspiração das secreções pulmonares.

Com base no conhecimento das complicações das vias aéreas e da fisiopatologia das lesões de mucosa relacionadas à intubação endotraqueal, medidas profiláticas simples e práticas podem ser adotadas durante a assistência ao paciente intubado ou traqueotomizado, as quais, seguramente, garantem a redução no índice de morbidade das vias aéreas.

\section{REVSÃO DA LITERATURA}

A partir da década de 60 , grande número de publicações enfocou as diversas lesões de mucosa das vias aéreas superiores decorrentes da intubação endotraqueal, causadas por intubações difíceis, traumáticas e prolongadas ou pela compressão da mucosa pelo balonete da cânula ${ }^{1-4}$. Para fins didáticos, as várias lesões serão relacionadas em três categorias: lesões ocorridas durante a introdução da cânula de intubação, lesões secundárias ao contato da cânula ou de seu balonete sobre as estruturas das vias aéreas e lesões decorrentes do prejuízo ao condicionamento do ar inalado.

\section{Lesões ocorridas durante a introdução da cânula de intubação}

Logo na introdução da cânula por via oral, durante as tentativas de exposição da glote com o laringoscópio, são descritas lacerações em lábios, gengivas, úvula, palato, amígdalas, faringe, epiglote, pregas vocais, esôfago e traquéia, hematomas e avulsão de pregas vocais, deslocamento e luxação de cartilagens aritenóideas 5 . Essas lesões agudas ocorrem, normalmente, com profissionais inexperientes e em situações de emergência, que exigem rapidez no acesso das vias aéreas (Figura 1 ).

Dependendo da sua extensão, as lacerações em mucosa oral e faríngea podem causar importante disfagia. Lesões na mucosa de estruturas cartilaginosas, como a epiglote, as aritenóideas e a cricóidea, podem evoluir para pericondrite e cursar com febre, otalgia, disfagia e até mesmo imobilidade das estruturas glóticas, em conseqüência de condrite da junção cricoaritenóidea ${ }^{6}$.

As perfurações de esôfago podem causar mediastinite e abscesso ${ }^{7}$. As lacerações da mucosa traqueal ocorrem, principalmente, na porção membranosa e podem causar pneumomediastino ${ }^{8}$. Fraturas e avulsões de dentes, principalmente dos incisivos superiores, também podem ocorrer e originam-se do apoio traumático da lâmina do laringoscópio, durante as tentativas de exposição da glote, principalmente em laringes em posição cervical muito anterior.

Em intubações nasotraqueais pode ocorrer laceração de mucosa do vestíbulo nasal, dos cornetos e da rinofaringe, provocando epistaxe, por vezes volumosa. Lesões isquêmicas em pele e cartilagens do vestíbulo nasal, decorrentes da fixação inadequada da sonda no local, também são relatadas 5 .

\section{Lesões secundárias ao contato da cânula ou de seu balonete sobre as estruturas das vias aéreas}

Pesquisas clínicas têm demonstrado diversos tipos de lesões de mucosa laríngea e traqueal após a intubação por períodos variáveis de tempo, sendo este um dos fatores determinantes do agravamento das lesões,10. Devido à configuração da glote em " $V$ ", as principais lesões ocorrem na porção posterior da laringe, no nível dos processos vocais, onde a sonda encontra-se em íntimo contato com a mucosa. Exames endoscópicos realizados logo após a extubação permitem identificar ulceração superficial neste local, que evolui com rápida reparação tecidual (Figura 2). Alguns pacientes desenvolvem granulomas, em geral bilaterais e pediculados, que se inserem na face interna de ambas as apófises vocais. Esses granulomas são responsáveis por disfonia persistente e nem sempre regridem espontaneamente, exigindo remoção cirúrgica (Figura 3$)^{11}$.

O contato contínuo e traumático da sonda na região da glote posterior pode resultar em ulceração da região envolvendo o epitélio da mucosa interaritenóidea, cicatrização com fibrose e fixação das cartilagens aritenóideas na linha mediana, simulando quadro de paralisia bilateral das pregas vocais. Nesses casos, o exame de laringoscopia direta e a eletromiografia do músculo vocal são decisivos no esclarecimento do diagnóstico 6 .

0 diâmetro inadequado das sondas de intubação e a dificuldade em manter imobilizado o paciente intubado são fatores predisponentes ao desenvolvimento de lesões de 
vias aéreas. Movimentos constantes de flexão, extensão e lateralização cervical, realizados pelo paciente em estado de agitação, provocam friç̧ão da sonda e de seu balonete ao longo do trato respiratório. No paciente sem sedação estão presentes também movimentos reflexos de deglutição e de adução das pregas vocais sobre o tubo traqueal. Assim, quanto maior o tempo da intubação, maior o risco de ocorrência dessas lesões.

Lesões ulceradas envolvendo a região glótica podem ser observadas também durante a auto-extubação do paciente com o balonete insuflado.

A mucosa traqueal, em contato com o balonete da cânula, é particularmente vulnerável a lesões isquêmicas. Os balonetes das sondas de intubação mais antigas comportam baixo volume de ar, são de baixa complacência e de alta pressão. Esses balonetes foram, gradativamente, substituídos por balonetes mais complacentes e mais extensos. Por serem maiores, distribuem a pressão em área mais extensa, diminuindo a possibilidade de lesão da mucosa traqueal.

Vários autores têm estudado as lesões de mucosa relacionadas à elevada pressão no balonete das sondas endotraqueais. Nordin $(1977)^{1}$ realizou criterioso estudo experimental em ratos intubados, variando a pressão, no balonete, de 20 a $100 \mathrm{mmHg}$. Observou que, quando a pressão ultrapassava a pressão de perfusão capilar ( 25 $\mathrm{mmHg}$ ), iniciava-se um processo de isquemia sobre a mucosa, que era tanto maior quanto mais elevada fosse a pressão. 0 autor observou erosão extensa do epitélio respiratório com a utilização de pressões de 100 mmH g, estendendo-se também para as regiões intercartilaginosas. Essas áreas apresentaram também colonização de bactérias e condrite.

Em pacientes que necessitam de períodos prolongados de intubação endotraqueal, como em casos de insuficiência respiratória crônica e em pacientes neurológicos, a falta de controle da pressão no interior do balonete pode resultar em isquemia permanente da mucosa, dilatação traqueal e cicatrização com estenose (Figuras $4 a$ e 4b) ${ }^{12}$. 0 desenvolvimento dessas lesões é diretamente proporcional ao tempo de intubação. Segundo Whited $(1979)^{13}$, os riscos de desenvolvimento de estenose são mínimos com menos de seis dias de intubação (menos de $2 \%$ dos casos), tornando-se representativos acima de dez dias ( $12 \%$ a $15 \%$ dos casos).

Em estudo experimental em cães anestesiados e submetidos à intubação endotraqueal por apenas quatro horas, pudemos demonstrar, por meio de análise histológica do epitélio traqueal na área de contato com a sonda de intubação, lesões precoces sobre a mucosa traqueal, como erosões superficiais e infiltrado de células polimorfonucleares neutrófilos (Figura 5) ${ }^{14}$. Achados semelhantes haviam sido documentados por Alvarez e Aragón (1981) ${ }^{15}$ em análise de fragmentos de traquéia de pacientes submetidos a traqueotomia e que haviam sido mantidos intubados por, no máximo, 48 horas. No local de erosão da mucosa os autores identificaram depósito de fibrina e início de processo de reparação.

Sabe-se que alguns pacientes desenvolvem estenose traqueal mesmo permanecendo intubados por curtos períodos. Assim, reconhece-se a participação de outros fatores no desenvolvimento das estenoses traqueais, como infecções do trato respiratório, uso de corticóides sistêmicos, instabilidade hemodinâmica, hipoproteinemia, hipoxemia, anemia e doenças dos cílios imóveis ${ }^{16}$.

A medida da pressão do balonete não é realizada rotineiramente no centro cirúrgico ou nas unidades de terapia intensiva. A estimativa da pressão do balonete, por meio da palpação do balonete de prova, também não detecta pressões elevadas. A importância da monitorização da pressão no interior do balonete vem sendo evidenciada por alguns autores, por ser manobra simples, de baixo custo, realizada com manômetro digital portátil ${ }^{4,17,18}$.

Ainda não existe consenso sobre o valor máximo de pressão no balonete do tubo traqueal para se evitar lesão. Os valores críticos de pressão no balonete têm sido considerados de 25 a $30 \mathrm{cmH}_{2} \mathrm{O}$, próximos à pressão de perfusão capilar ${ }^{3,4}$.

Em nosso meio, Castilho et al. (2003) ${ }^{4}$, em recente estudo experimental em cães, realizou análise histológica da mucosa traqueal no local de contato com o balonete, utilizando, em um grupo de animais, pressão no balonete de $25 \mathrm{cmH}_{2} \mathrm{O}$, e no outro grupo, pressão de "selo" de 13 $\mathrm{CmH}_{2} \mathrm{O}$ (pressão mínima que permitia a ventilação artificial). Os autores observaram, em ambos os grupos, lesões epiteliais importantes quando comparadas ao epitélio respiratório normal, como áreas de erosão superficial com queda dos cílios (Figuras 6a e 6b). 0 estudo confirma a importância da manutenção da pressão no balonete inferior à pressão de perfusão capilar, uma vez que os autores detectaram lesões, embora superficiais, no epitélio respiratório, mesmo com níveis muito baixos de pressão no interior do balonete.

A pressão no interior do balonete da sonda pode aumentar durante a anestesia, pela difusão de gases anestésicos para o seu interior, como ocorre com o óxido nitroso, logo nas primeiras horas após o início da anestesia. Para evitar a expansão do balonete foi desenvolvida uma sonda de intubação provida de válvula de escape de ar (válvula de Lanz) (Figura 7). Nesse tipo de sonda, o tubo traqueal é dotado de uma válvula de redifusão, que permite que a pressão no interior do balonete não ultrapasse 25 a 30 $\mathrm{CmH}_{2} \mathrm{O}$. Com o objetivo de estudar a eficácia desse novo protótipo de balonete, Navarro et al. (2001) ${ }^{18}$ realizaram medidas das pressões nos balonetes das sondas de intubação de 40 pacientes anestesiados com óxido nitroso, sendo 20 submetidos a intubação com tubos convencionais providos de balonetes de baixa pressão e 20 intubados com tubos dotados de válvula de Lanz. Não se constatou aumento da pressão no interior do balonete apenas no grupo de pacientes que utilizou tubos endotraqueais com válvula de Lanz. 
Embora existam comprovações da eficácia dos tubos com a válvula de Lanz, o custo dessa sonda é ainda muito elevado, o que inviabiliza sua utilização na rotina hospitalar.

Uma tentativa de impedir a difusão do óxido nitroso para o interior do balonete é a introdução de solução de lidocaína ou soro fisiológico no seu interior. Pesquisas clínicas têm demonstrado a eficácia desses métodos, observando-se também redução na ocorrência dos sintomas de odinofagia e disfagia no período pós-operatório e diminui- ção de reação ao tubo traqueal no caso de ser utilizada a lidocaína ${ }^{19}$. 0 principal inconveniente do método é o risco de ruptura acidental do balonete da sonda e aspiração de grande quantidade de líquido para o interior das vias aéreas.

O utra tentativa de minimizar o índice de morbidade associada à intubação endotraqueal é a utilização da máscara laríngea (Figura 8), a qual passou a ser utilizada, inicialmente, em situações de emergência, em virtude de sua fácil introdução, mesmo nas mãos de profissionais inexperi-
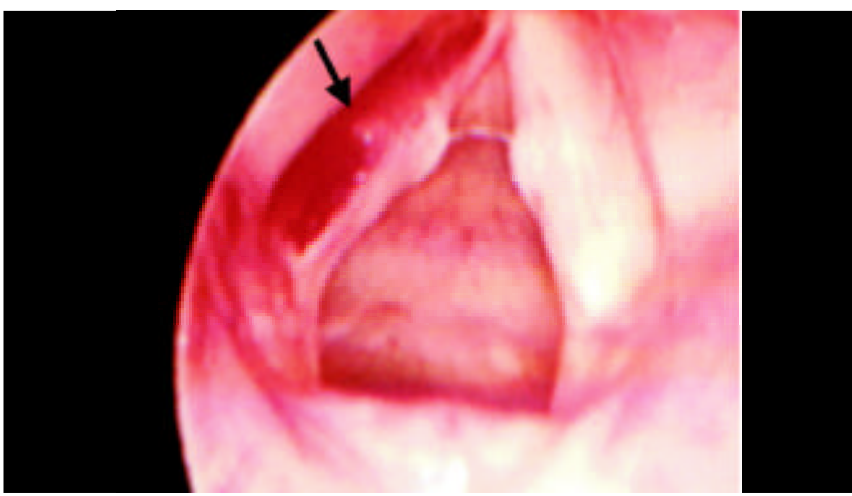

Figura 1. Laceração e hematoma em prega vocal esquerda durante laringoscopia direta. Exame realizado com telescópio rígido.

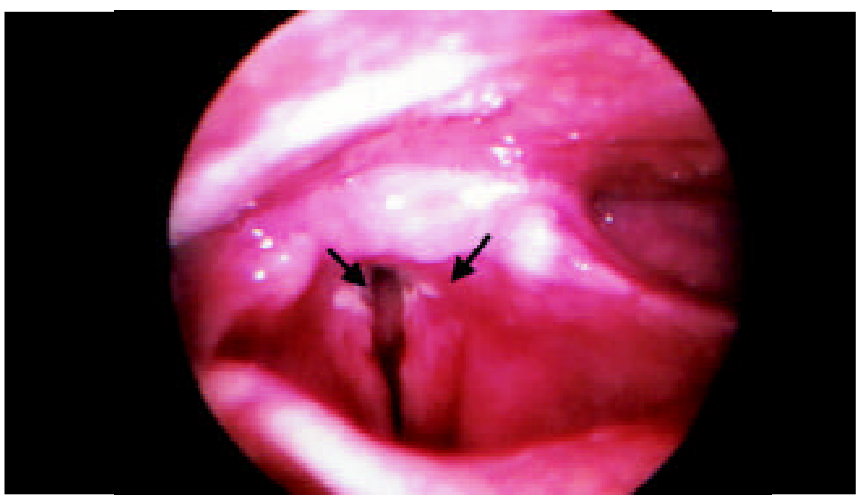

Figura 2. Lesões ulceradas presentes em comissura glótica posterior, observadas logo após a extubação. Exame realizado com telescópio rígido.

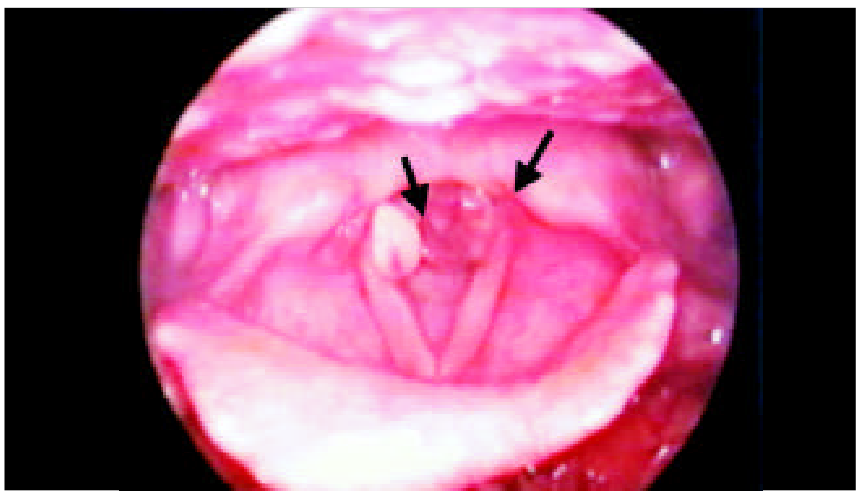

Figura 3. Granulomas de intubação bilaterais inseridos nas apófises vocais. Exame realizado com telescópio rígido.

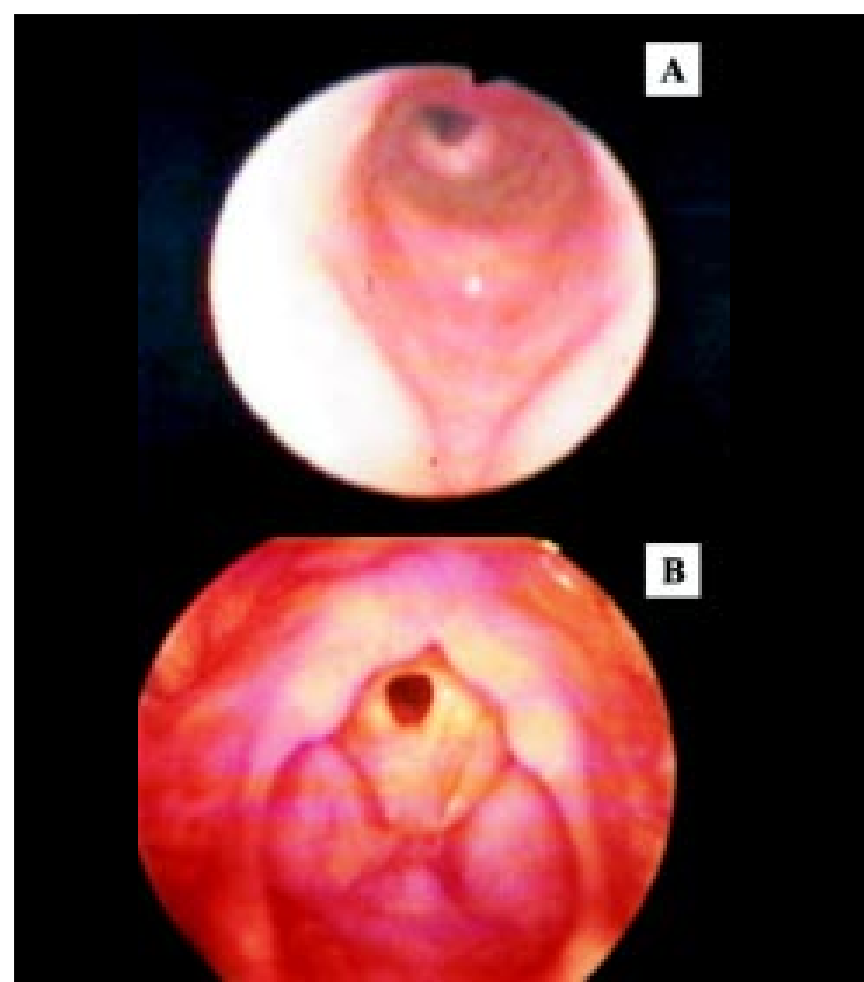

Figura 4. a - estenose traqueal (exame realizado com nasofibroscópio flexível); b - estenose glótica (exame realizado com telescópio rígido).

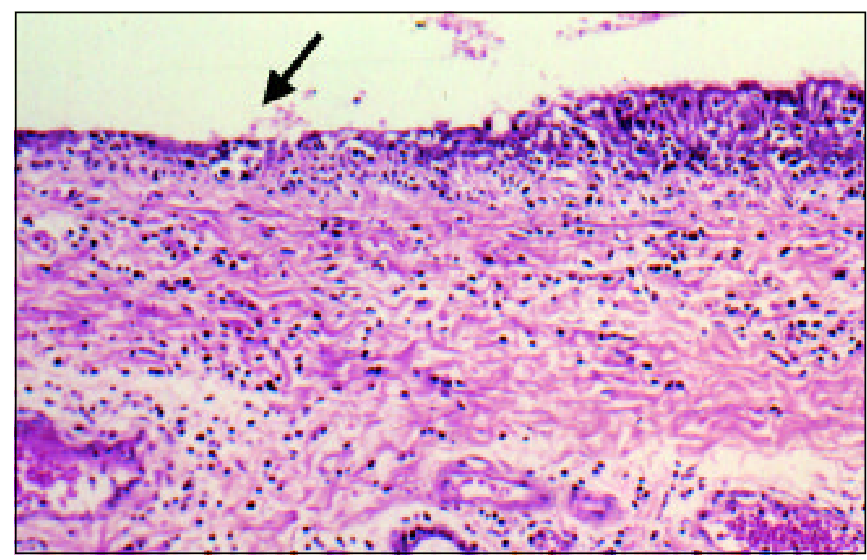

Figura 5. Corte histológico de epitélio traqueal do cão mostrando ulceração superficial na região do balonete da sonda endotraqueal (20X, hematoxilina-eosina-HE). 
entes. Ao longo dos anos as vantagens superaram as expectativas e permitiram sua utilização na rotina hospitalar. A principal vantagem da máscara é que, após sua introdução, ela se acomoda na hipofaringe e não faz contato com a região da glote, o que reduz a ocorrência dos sintomas de rouquidão e disfagia no pós-operatório ${ }^{20}$. Por este motivo, a máscara laríngea passou a ser a primeira escolha em anestesia de profissionais da voz ${ }^{21}$.

Ressalte-se, ainda, que a região da hipofaringe, onde permanece insuflado o balonete da máscara laríngea após a inserção, é bastante distensível e adaptada à função de deglutição, recebendo variáveis volumes de bolo alimentar. Assim, como a pressão no interior do balonete não é transmitida integralmente à mucosa, diminui a incidência de isquemia de mucosa e de estenose ${ }^{22}$.

Em estudo experimental com cães anestesiados, utilizamos a máscara laríngea com diferentes pressões no interior de seu balonete (grupo I $119 \mathrm{mmHg} \pm 4$; grupo II - 234 $\mathrm{mmHg} \pm 13$ ) e realizamos análise histológica e de microscopia eletrônica de varredura da região da hipofaringe em contato com o balonete da sonda. O bservamos, em ambos os grupos, discreta congestão do epitélio de cobertura, processo inflamatório agudo e pequenas áreas de ulceração superficial da mucosa, mesmo no grupo de alta pressão no balonete (Figuras 9a e 9b) ${ }^{23}$. Embora não tenhamos constatado grandes alterações na mucosa da laringofaringe em contato com a máscara laríngea, vários autores fazem referência a complicações com a utilização dessa máscara, como edema, cianose e paralisia de língua ${ }^{24}$, paralisia de pregas vocais ${ }^{25}$, laceração em úvula e palato ${ }^{26}$.

\section{Lesões decorrentes do prejuízo ao condicionamento do ar inalado}

A maior parte do condicionamento do ar inspirado ocorre no interior das fossas nasais e da rinofaringe. Nestes sítios o ar é umidificado e aquecido e depurado de grande número de partículas poluentes e de microorganismos presentes no ar ambiente, que se aderem à camada de muco que recobre todo o epitélio respiratório. Graças à atividade mucociliar, essas partículas são impulsionadas em direção ao trato digestivo para serem deglutidas e eliminadas. No paciente intubado ou traqueotomizado o ar inalado chega dire-

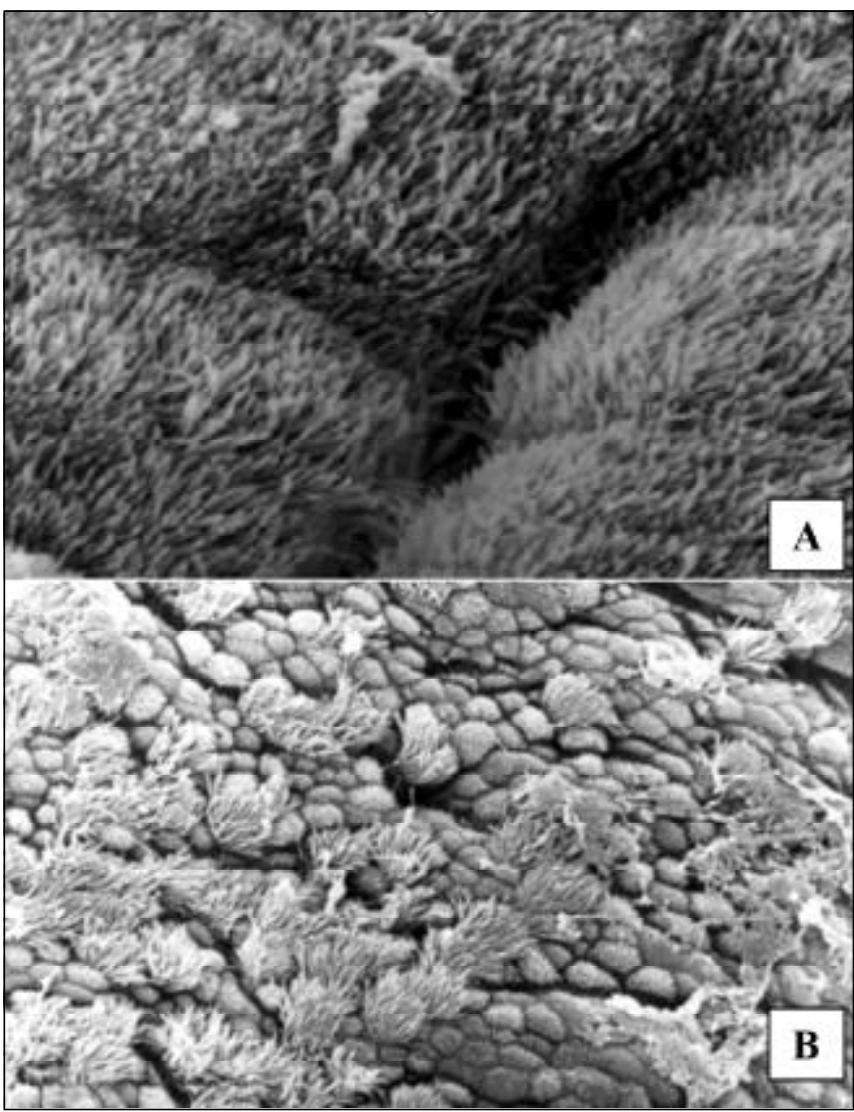

Figura 6. a - Superfície normal do epitélio traqueal do cão. Notar a distribuição homogênea do tapete ciliar. (Microscopia eletrônica de varredura, 750X); b - Áreas do epitélio traqueal com perda de cílios. Cílios remanescentes desorganizados e agrupados. (Microscopia eletrônica de varredura, 1500X)

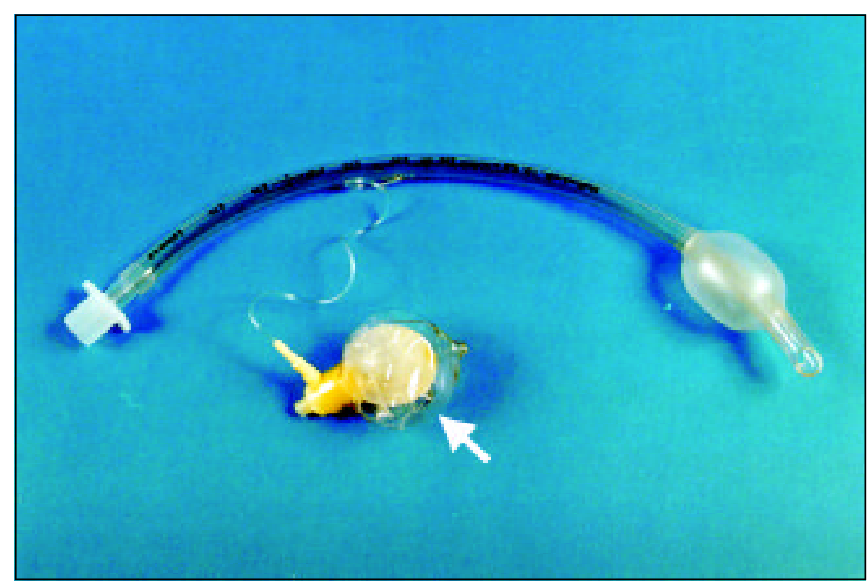

Figura 7. Tubo traqueal provido de váLvula de Lanz (seta).

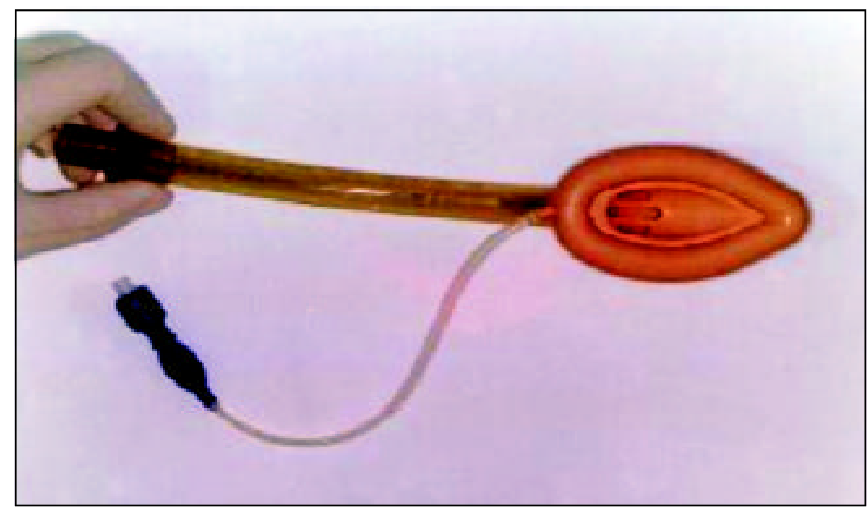

Figura 8. Máscara laríngea. 

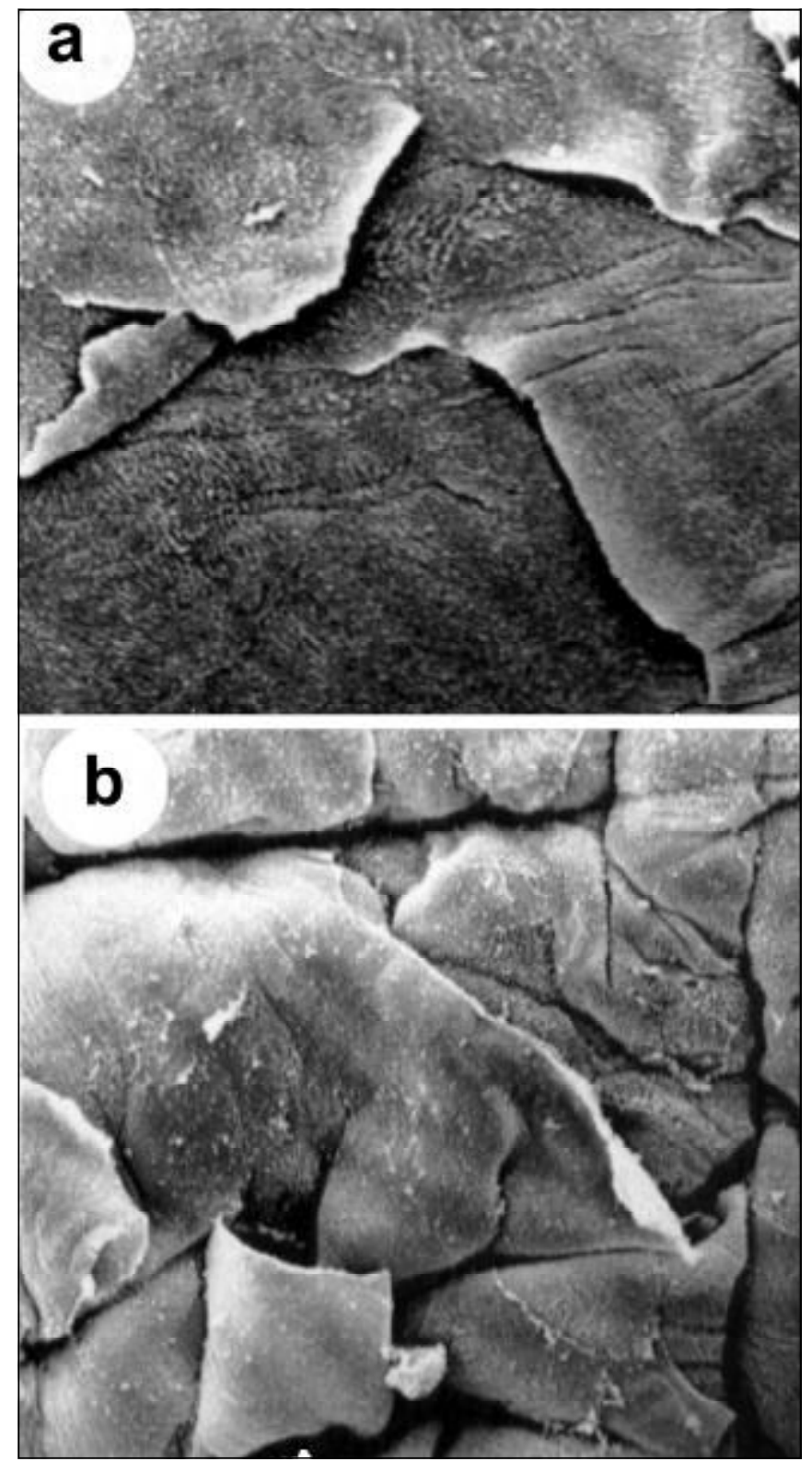

Figura 9. Microscopia eletrônica de varredura do epitélio pavimentoso estratificado da região da hipofaringe em contato com o balonete da máscara laríngea. Observam-se áreas de descamação epitelial superficial. Em a, 1260 X; em b, $1570 \mathrm{X}$.

tamente à traquéia, sem prévio condicionamento. Entre as principais conseqüências da inalação de ar seco e frio destacam-se os danos ao epitélio, com edema de mucosa das vias aéreas, discinesia ciliar e estase de secreções ${ }^{27}$.

Marfatia et al. (1975) ${ }^{28}$ analisaram o epitélio respiratório de ratos expostos à ventilação mecânica com gases secos e frios e observaram destruição de células ciliadas, áreas de desorganização do epitélio respiratório e espessamento de muco. Evidenciaram, ainda, aumento na resistência das vias aéreas, diminuição na complacência pulmonar, alteração na composição do surfactante e infiltrado inflamatório intersticial pulmonar.

Com o objetivo de analisar os efeitos da temperatura e da umidade do ar inalado sobre o epitélio respiratório, realizamos estudo experimental em cães submetidos a ventilação mecânica e a inalação de ar a diferentes temperaturas (27 a $36^{\circ} \mathrm{C}$ ) e graus de umidade absoluta (17 a $36 \mathrm{mgH}_{2} \mathrm{OL}^{-1}$ ) durante período de quatro horas ${ }^{29}$. No estudo histológico de biópsias da mucosa da árvore traqueobrônquica observamos, no grupo de animais ventilados com gases frios e com baixa umidade, infiltrado de células polimorfonucleares na superfície do epitélio e no córion, além de congestão e hemorragia. 0 epitélio respiratório encontrava-se normal no grupo de animais ventilados com gases aquecidos à temperatura entre 32 e $36^{\circ} \mathrm{C}$ e umidificação entre 30 e $36 \mathrm{mgH}_{2} \mathrm{OL}^{-1}$.

Mesmo após a comprovação, por numerosas publicações, da morbidade do trato respiratório exposto ao ar pouco condicionado, não é rotina no centro cirúrgico, mesmo em cirurgias prolongadas, o uso de umidificadores aquecidos acoplados aos sistemas de ventilação, os quais estão disponíveis, na maioria dos serviços, apenas nas unidades de terapia intensiva.

Os permutadores de calor e de umidade, denominados de "narinas artificiais", são pequenos dispositivos acoplados ao sistema de ventilação, constituídos de filtros capazes de reter calor e umidade, eliminados durante a expiração e reaproveitados na inspiração. Em pesquisa experimental em cães, Bisinotto et al. (1999) ${ }^{30}$, por meio de estudos histológicos e de microscopia eletrônica de varredura de peças de biópsia da árvore traqueobrônquica, demonstraram a habilidade dos permutadores no condicionamento do ar inalado, bem como na manutenção da integridade do epitélio respiratório. No grupo de animais sem o dispositivo os autores registraram valores baixos de calor e de umidade no ramo inspiratório do sistema de ventilação e lesões histológicas no epitélio respiratório, como agrupamentos e quedas dos cílios, além de ressecamento e ruptura das gotas de muco.

\section{DISCUSSÃO}

As complicações das vias aéreas secundárias à intubação endotraqueal são freqüentes, muitas delas com sintomas leves e de curta duração. Entretanto, em muitos casos as lesões são graves e permanentes, envolvendo as estruturas da laringe e da traquéia, e exigem correção cirúrgica, como ocorre na estenose glótica e traqueal.

A respiração por meio de uma sonda traqueal não é fisiológica, porém necessária, em muitas situações. 0 conhecimento da morbidade das vias aéreas relacionada à intubação e a compreensão da fisiopatologia das lesões e dos fatores predisponentes associados permitem-nos adotar medidas profiláticas, que certamente auxiliarão na redução dessas complicações. 
As pesquisas clínicas e experimentais, relatadas no trabalho, permitem a adoção de recomendações para com o paciente intubado, tais como: cautela e habilidade na introdução da sonda, escolha do calibre ideal, opção pelos novos protótipos de sondas com balonetes mais complacentes e mais maleáveis, imobilização adequada dos pacientes, cuidados na aspiração traqueal, monitorização permanente da pressão no interior do balonete, adaptação de umidificadores aquecidos ou de permutadores de calor e de umidade.

\section{COMENTÁRIOS FINAIS}

As complicações das vias aéreas associadas à intubação endotraqueal são freqüentes e muitas vezes graves. A incidência dessas lesões pode diminuir a partir do conhecimento da sua fisiopatologia, o que nos permite adotar medidas profiláticas que devem ser do conhecimento de todos os profissionais de saúde que dão assistência ao paciente intubado.

\section{REFERÊNCIASBIBLIOGRÁFICAS}

1. Nordin U. The trachea and cuff-induced tracheal injury. Acta Otolaryngol 1977; 345(suppl):1-71.

2. Stauffer J, OIsen D, Petty HT. Complications and consequences of endotracheal intubation and tracheostomy. Am J Med 1981; 70:6576.

3. Guyton DC, Barlow MR, Besselievre TR. Influence of airway pressure on minimum occlusive endotracheal tube cuff pressure. Crit Care Med 1997; 25:91-4.

4. Castilho EC, Braz JRC, Martins RHG, Gregório E. Efeito da pressão limite de $25 \mathrm{mmH}_{2} \mathrm{O}$ e mínima de selo do balonete de tubos traqueais sobre a mucosa traqueal do cão. Rev Bras Anestesiologia 2003; 53:743-55.

5. Lacau Saint Guily J, Boisson-Bertrand D, Monnier P. Lésions liées à l'intubation oro- et nasotrachéale et aux techniques alternatives: lèvres, cavités buccale et nasales, pharynx, larynx, trachée, oesophage. Annales Françaises d'Anesthésie et de Réanimation 2003; 22:81-96.

6. Gacek RR, Gacek MR, Montgomery WW. Evidence for laryngeal paralysis in cricoarytenoid joint arthritis. Laryngoscope 1999; 109:279-83

7. Ku PKM, Tong MCF, Ho KM, Kwan A, Van Hasselt CA. Traumatic esophageal perforation resulting from endotracheal intubation. Anesth Analg 1998; 87:730-1.

8. Molins L, Buitrago LJ, Vidal G. Tracheal lacerations after intubation. Chest 1998; 114:1793-4.

9. John SJ, Matsura $\mathrm{H}$, Kotani $\mathrm{Y}$, et al.. Change in tracheal blood flow during endotracheal intubation. Acta Anaesthesiol Scand 1987; 31:300-4.
10. Brichet $A$, Ramon $P$, Marquette $\mathrm{CH}$. Sténoses et complications trachéales postintubation. Réanimation 2002; 11:1-10.

11. Pontes PAL, De Biase NG, Gadelha MEC. Clinical evolution of laryngeal granulomas: treatment and prognosis. Laryngoscope 1999; 109:289-94.

12. Luna CM, Legarreta G, Esteva H, Laffaire E, Jolly EC. Effect of tracheal dilatation and rupture on mechanical ventilation using a low-pressure cuff tube. Chest 1993; 104:639-40.

13. Whited RE. Laryngeal dysfunction following prolonged intubation. Ann Otol Rhinol Laryngol 1979; 88:474-8.

14. Martins RHG, Braz JRC, Bretan O, Defaveri J. Lesões precoces da intubação endotraqueal. Rev Bras Otorrinolaringologia 1995; 44:181-85.

15. Alvarez AC, Aragón JA. Alteraciones precoces de la mucosa traqueal, producidas por la intubación observadas mediante el microscopio electrónico de barrido (M.E.B.). An. Otorrinolaringol Ibero-Am 1981; 5:369-80.

16. Yang KL. Tracheal stenosis after a brief intubation. Anesth Analg 1995; 80:625-7.

17. Braz JRC, Navarro LHC, Takata IH, Nascimento P. Endotraqueal tube cuff pressure need for precise measurement. Med J 1999; 117:243-47.

18. Navarro LHC, Braz JRC, Pletsh AK, Amorim RB, Módolo NSP. Estudos comparativos das pressões de balonetes de tubos traqueais, contendo ou não válvula geradora de pressão de Lanz. Rev Bras Anestesiologia 2001; 51:17-27.

19. Estebe J-P, Dollo G, Corre PL, et al. Alkalinization of intracuff lidocaine improves endotracheal tube-induced emergence phenomena. Anesth Analg 2002; 94:227-30.

20. Brimacombe J, Berry A. The laryngeal mask airway - the first tem years. Anaesth Intensive Care 1993; 21:225-6.

21. Zimmert $M$, Zwirner $P$, Kruse $E$, Braun U. Effects on vocal function and incidence of laryngeal desordes when using a laryngeal mask airway in comparation with an endotracheal tube. Eur J Anaesthesiol 1999; 16:511-5.

22. Marjot R. Pressure exerted by the laryngeal mask airway cuff upon the pharyngeal mucosa. Br J Anaesth 1993; 70:25-9.

23. Martins RHG, Braz JRC, Abud TMV. Effect of high laryngeal mask airway intracuff pressure on the laryngopharyngeal mucosa. Laryngoscope 2000; 110:645-50.

24. Laxton $\mathrm{CH}$. Lingual nerve paralysis following the use of the laryngeal mask airway. Anaesthesia 1996; 51:869-70.

25. Fawcett WJ, Daya H, Weir N. Recurrent laryngeal nerve palsy and the laryngeal mask airway (letter). Anaesthesia 1996; 51:708.

26. Lee JJ. Laryngeal mask and trauma to uvula. Anaesthesia 1989; 44:1014-5.

27. Chalon J, Loew DAY, Malebranche J. Effects of dry anesthetic gases on tracheobronchial ciliated epithelium. Anesthesiology 1972; 37:338-43.

28. Marfatia S, Donahoe PK, Hendren WH. Effect of dry and humidified gases on the respiratory epithelium in rabbits. J Pediatr Surg 1975; 10:560-83.

29. Martins RHG, Braz JRC, Defaveri J. Estudo da umidificação e do aquecimento dos gases inspirados durante ventilação mecânica no cão. Rev Bras Otorrinolaringologia 1996; 62:206-18.

30. Bisinotto FMB, Braz JRC, Martins RHG, Gregório EA, Abud TMV. Tracheobronchial consequences of the use of heat and moisture exchanges in dogs. Can J Anesth 1999; 46:897-903. 